\title{
The Correlation between Motor Vehicle Lease Program and the Efficiency of Police Operations in Kayole Sub County, Nairobi, Kenya
}

\author{
Noor Yarow Gabow ${ }^{1}$ and Muraya Karanja Justus ${ }^{2}$ \\ ${ }^{1}$ Africa Nazarene University, Kenya; ${ }^{2}$ Africa Nazarene University, Kenya
}

\begin{abstract}
The objective of this study is to examine the link between motor vehicle lease program for police and the efficiency of police operations in the Kayole Sub County of Nairobi County. The study conceptualises that motor vehicle lease program for police indicated by the number of vehicles, quality of vehicles, and type of vehicles leads to efficiency in police operations as shown by a reduction in crime incidences, public safety, and reduced fear of crime among others. This study used the descriptive survey design. Data were collected from 196 respondents sampled from 400 respondents. These were sampled using the using stratified proportionate sampling technique. The rationale behind the choice of Kayole Sub-County was owing to its being rated as a crime hot spot. This study used interviews, questionnaires, and focused group discussions methods for data collection. Quantitative data was analysed using quantitative analysis methods while qualitative data was analysed using qualitative data analysis methods, triangulation method. The findings show that there is a link between motor vehicle lease program and efficiency of police operation where an increase in utilisation of leased motor vehicles would increase the efficiency of police operations. It was thus necessary to have enough and astute vehicles that could enhance the ability of vehicles to dispense their duties with ease. This is pertinent since this can enable their efficiency. Various policy recommendations were made. To begin with, the study recommends that the Kenya police service (KPS) should ensure increased use of motor vehicle lease program which has been established as enhancing the efficiency of police operations in Kenya. There is need to improve response time and visible presence of the police using new police vehicles, to further improve on their service delivery. The KPS should actively adopt a motor vehicle lease program to enhance efficiency and effective use of resources and considerably reduce operational costs. This would provide a competitive edge by increasing productivity and reducing waste. Additionally, the KPS should provide regular training of its procurement officer about the leasing program essentials for proper motor vehicle lease program arrangement that would optimise benefits from the program. There is also need for changing the legal and institutional framework to strengthen the laws and regulations on leasing to spur the development of leasing in the country.
\end{abstract}

Key Words: Efficiency of police operations, Police Service, Motor vehicle leasing program.

\section{INTRODUCTION}

Extant literature shows that enhancing the availability of vehicles among police officers from leases leads to police efficiency (De Jong, 2017; Spencer \& Webb, 2015). The present study assessed the effect of lease terms on crime reduction by the Kenya Police Service (KPS). In Ethiopia, Olana (2016) shows that lease financing influences service delivery. Though Olana (2016) focused more on lease companies instead of the leasing companies, the findings show that leasing can enhance the efficiency of service delivery.

In Zambia, Alyosius and Lubinda (2013) revealed that the major challenges experienced by the lease providers included the lack of a leasing program and leasing laws. This could lead to failures in service delivery. It is in this backdrop that this study sets out to investigate the effects of lease programs on service delivery by KPS. The presence of police patrols in the Kilifi County of Kenya had led to enhanced security in the area; leading to the expansion of businesses (PKF Consulting Limited, 2017).

Still, in Kenya, reports from Wote town in Makueni County, show that increased police patrols had led to a reduction in crime. The presence of more patrols by the police as well as traffic lights had motivated businesses to operate for longer periods 
due to enhanced security (PKF Consulting Limited, 2017). It is against this backdrop that this paper examines the link between motor vehicle lease program for police and the efficiency of police operations.

\subsection{STATEMENT OF THE PROBLEM}

Vehicle lease programs increase the number of vehicles available for the police. A police officer in Kiambu owes their improvement in response time and visible presence to new police vehicles. He looks forward to being assigned vehicles from the pool of leased vehicles in the future to further improve on their service delivery. In Kisii, the leased vehicles greatly improved service delivery. Also, police patrol vehicles in Kisumu were frequently patrolling outside and had improved service delivery. The same was being experienced in Kakamega where the introduction of the vehicle leasing program had brought about better service delivery. In Kibera, the adoption of the vehicle leasing program had increased police patrols and was highly supporting business growth in the area (PKF Consulting Limited, 2017). However, the level to which the increased availability of leased vehicles contributes to the efficiency of police operations in various parts of Nairobi City County has not been systematically studied. This means that understanding the influence of vehicle lease programs on the efficiency of police operations in areas with high levels of insecurity in the county would remain a tall order. This presents a knowledge lacuna that cannot be bridged without studies such as this current one. This current study sets out to bridge this knowledge gap.

\subsection{OBJECTIVE OF STUDY}

The objective of this study is to examine the link between motor vehicle lease program for police and the efficiency of police operations in Kayole Sub-County in the Nairobi County of Kenya.

\subsection{Justification}

It is important to understand the influence of vehicle lease programs on the efficiency of police operations. The national police service will understand how the programs influence their operations. This will help them put in place mechanisms aimed at streamlining the program. The study would also be important for the national government since it could appreciate the importance of strengthening policies aimed at enhancing funding for motor vehicle lease programs. Other scholars could also find this study important since the findings obtained could inform follow up studies on motor vehicle lease programs.

\subsection{SCOPE OF THE STUDY}

The study only focused on the motor vehicles leased for the KPS by the government of Kenya for official police administrative functions and operations. The study was conducted in Kayole which is one of the sub-counties within Nairobi County. The area was chosen since it is highly affected by insecurity which necessitates rigorous policing.

\subsection{Conceptual Frame Work}

The study conceptualises that the motor vehicle lease program indicated by the number of vehicles, quality of vehicles, and type of vehicles leads to efficiency in police operations as shown by the reduction in crime incidences, public safety, and reduced fear of crime among others. This is shown in Figure 1.

Independent Variables

\begin{tabular}{|c|c|}
\hline $\begin{array}{l}\text { Motor vehicle lease program } \\
\text { - No. of vehicles } \\
\text { - Quality of vehicles } \\
\text { - Type of vehicles }\end{array}$ & $\begin{array}{l}\text { Efficiency of Police Operations } \\
\text { in Kayole Sub-County, Nairobi } \\
\text { County } \\
\text { - Reduce crime Incidences } \\
\text { - Public safety } \\
\text { - Reduced level of fear of crime }\end{array}$ \\
\hline
\end{tabular}

Figure 1. Conceptual Framework for the effect of vehicle lease program on the efficiency of police operations 


\section{LITERATURE REVIEW}

\subsection{Theoretical Framework}

This study was guided by the Situational Crime Prevention (SCP) Theory as explained by Clarke (1997). The SCP theory was useful for relating the efficiency of KPS in a crime-fighting quest through the use of the motor vehicle lease program. The theory was proposed by Clarke in 1980. It underscores the importance of crime prevention as opposed to the detection and punishment of criminals after the occurrence of crime (Gibbs, 2010). The theory postulates that influencing the decision process of the would-be criminals against engaging in criminal acts will help in the achievement of crime prevention (Clarke, 1997).

There is a distinction between interventions aimed at affecting the conduct of crime and those targeting motivation of crime. For criminals to engage in criminal acts, they weigh the benefits of engaging in crime versus the cost (Clarke, 1997). The police service therefore should focus on increasing the perceived cost by increasing the associated effort of engaging in a criminal act together with perceived risks (Beebe \& Rao, 2005).

The reduction of perceived benefits will be achieved by reducing anticipated benefits from the crime. It is the assumption of this study that the police service will only be effective when there is decreased criminal's perceived benefit due to the increasing presence of patrol cars which will be focusing on the settings in which crimes occur (Gibbs, 2010). Effectively, it is believed that the presence of police reduces the perceived benefits of engaging in a criminal act. The theory seeks to make crime less attractive and operates through a host of public agencies whose transport resources and operations deter opportunities and incentives for a vast range of different crimes.

\subsection{Empirical Review of Literature}

Globally, De Jong (2017) identified certain strategies including; spin-offs and increasing; variable leasing, franchising, and; management contracts as being useful determinants of leasing contracts. Meanwhile, Spencer and Webb (2015) found evidence that operating leases are used opportunistically considering that the lessor keeps all the risk associated with motor vehicles during the entire life of the contract. According to Spencer and Webb (2015), operating leases are favourably used as sources of financing. While the study by De Jong (2017) focused on real estate, the study by Spencer and Webb (2015) was too general making the applicability of their findings in the police service difficulty. Based on the findings from the studies by De Jong (2017) and Spencer and Webb (2015), the present assessed the effect of lease terms on crime reduction by the KPS.

Regionally, Olana (2016) found out that the major challenges of the lease finance sector in Ethiopia include; lack of leasing expertise in the market; procurement hurdles; the existence of limited domestic suppliers; and absence of a specialized leasing training centre in the country. The study recommends changes to the legal and regulatory framework to create an enabling environment for leasing development. Clarity of leasing laws and regulations as well as challenges of the leasing sector should be resolved by the concerted efforts of key stakeholders in a way that spurs the development of leasing in the country. Although the study by Olana (2016) revealed the challenges in lease financing, it failed to specify the influence of lease terms on the effectiveness of the service delivery form lease resources.

Further, Olana (2016) focused more on lease companies instead of the leasing companies. Alyosius and Lubinda (2013) revealed that the regulatory body in Zambia had not yet put enough effort into promoting leasing markets in Zambia. They noted that there is no leasing industry-specific legislation in the country. According to the study, the major challenges experienced by the lease providers in Zambia included the lack of a leasing program and leasing laws. There is no clarity on the effect of leased terms on service delivery. It is based on this knowledge gap that this present study assessed the effects of lease terms on service delivery by KPS using leased vehicles.

In Kilifi, a business school owner reckons that the frequent police patrol vehicles in the area had boosted confidence amongst pupils and teachers because they could walk freely to and from school. He looked forward to expanding his business (PKF Consulting Limited, 2017). A shopkeeper of Asian origin also noted the increased frequency in police patrols in his area, Hindi. With new lights on high masts, his business opened until $6.00 \mathrm{pm}$, unlike the past. While another businessman from the same area concurred with the general improvement in security, he also voiced his concerns about the vulnerability of officers to open gunfire, because of the design of the police vehicles.

Reports from Wote in Makueni County indicate that the response of the police to crime incidences as well as boda boda (Swahili for motorcycle taxis) accidents had immensely improved as witnessed by a community Security committee. These had seen an improvement in the interaction between the police and locals. Another businessman also noted the improvement in business climate owing to the presence of more patrols by the police and street lights. As a result, he was operating his business until as late as 11.00 pm (PKF Consulting Limited, 2017). 


\section{RESEARCH METHODOLOGY}

\subsection{Research Design}

This study used the descriptive survey design. This kind of design is useful since it significantly describes the variables of interest by analysing their relationships and providing valuable and accurate answers to the research questions (Kombo \& Tromp, 2006). This approach was most suitable in gathering information to examine the effects of the motor vehicle lease program for KPS on the efficiency of police operations in Nairobi County.

\subsection{Population}

The target population for this study was the serving police officers within Kayole Sub-County, community policing members, and members of the public in the Sub-County. The target population was 340 serving police officers in Kayole SubCounty, 10 community policing members, and 50 members of the public in Kayole. So, the target population was 400 respondents (PKF Consulting Limited, 2017). The rationale behind the choice of Kayole Sub-County was its being rated as a crime hot spot.

\subsection{Sample}

Using the formula proposed by Saunders, Lewis \& Thornhill (2012), the study obtained an adjusted minimum sample size of 196. The proportionate stratified sampling was used to establish the sample size for each category of respondents, which was determined as the ratio of respondents in the category to the target population in that category multiplied by the sample size as shown in Table 1.

Table 1 Distribution of the Sample Size

\begin{tabular}{|l|l|l|}
\hline Category & Target Population & Sample size \\
\hline Senior Police Officers & 27 & $=\left(27^{*} 196 / 400=13\right.$ \\
\hline Non-Commissioned Officer (NCO) & 95 & $=\left(95^{*} 196\right) / 400=47$ \\
\hline Constables & 218 & $=\left(218^{*} 196\right) / 400=107$ \\
\hline Community policing members & 10 & $=\left(10^{*} 196\right) / 400=5$ \\
\hline Members of public & 50 & $=\left(50^{*} 196\right) / 400=24$ \\
\hline Total & 400 & 196 \\
\hline
\end{tabular}

\subsection{Data Analysis}

This study used interviews, questionnaires, and focused group discussions methods for data collection. The collected data were first checked for errors of omission and commission. Then it was classified and coded accordingly. The study analysed quantitative data using quantitative analysis methods while qualitative data were analysed using qualitative data analysis methods, triangulation method. Qualitative analysis technique was used to analyses data through coding and organizing it into themes aimed at gaining real, rich, and deep results. The results were reported in narrative form. Thus, the qualitative analsis used themes (thematic analysis) based on the indicators of the variables. The quantitative analysis method was used to produce descriptive statistics (means and standard deviations) to quantify and establish relationships. The results from descriptive statistics were presented in tables.

\section{RESULTS AND ANALYSIS}

\subsection{Introduction}

This chapter contains the results obtained from the analysis of the data collected in the study. The main methods of analysis were qualitative and quantitative.

\subsubsection{Link between motor vehicle lease program and the efficiency of police operations}

This section presents findings on the link between motor vehicle lease program and the efficiency of police operations. The study tools contained questions that were both open and closed-ended. The closed-ended question was collected using a 5point Likert scale; "Strongly Disagree $=1$ : Disagree $=2:$ Neutral $=3:$ Agree $=4:$ Strongly Agree $=5$." This study obtained means (M) and standard deviation (SD) of these results for simplicity in interpretations and presentations. On obtaining the Ms and SDs for each indicator, the study the moderated the same using the statistics; $1-1.8$ for Strongly Disagree; above $1.8-2.6$ for Disagree; above 2.6 - 3.4 for Neutral; above $3.4-4.2$ for Agree; and above 4.2 - 5.0 for strongly Agree. The moderation enhanced ease in the interpretation of the results captured in Table 2. 
International Journal of Advances in Scientific Research and Engineering (ijasre), Vol 6 (6), June -2020

Table 2: Link between motor vehicle lease program and efficiency of police operations

\begin{tabular}{|l|l|l|}
\hline Relationship between motor vehicle lease program and efficiency & M & SD \\
\hline Vehicle tracking and monitoring & 3.54 & 0.91 \\
\hline Fleet management of both driver and the assets & 3.63 & 1.00 \\
\hline Fuel consumption of the motor vehicle lease & 3.33 & 0.92 \\
\hline Customized financing reduced wastage of resources & 3.59 & 0.97 \\
\hline Overall link between motor vehicle lease program and efficiency & $\mathbf{3 . 5 2}$ & $\mathbf{0 . 9 5}$ \\
\hline
\end{tabular}

The results in Table 2, show that the respondents agreed that there was a significant link between motor vehicle lease program and efficiency of police operation $(\mathrm{M}=3.54 ; \mathrm{SD}=0.91)$. This was supported by the respondents indicating that they agreed that Vehicle tracking and monitoring used in the motor vehicle lease program ensured that the police officer was at the destination in time $((\mathrm{M}=3.54 ; \mathrm{SD}=0.91)$. They agreed that fleet management of both drivers and the assets enhanced productivity of the police service $(\mathrm{M}=3.63 ; \mathrm{SD}=1.00)$. However, they were neutral on the assertion that fuel consumption of the motor vehicle lease program was lower which increased the efficiency of police operations $(\mathrm{M}=3.33$; 0.92) but they agreed that customized financing reduced wastage of resources, therefore, improving the efficiency of police operations $(\mathrm{M}=3.59$; SD $=0.97)$.

Further, the police officers indicated that the adoption of leased motor vehicles increased the number of motor vehicles, which ensured the availability of properly maintained motor vehicles to the police officers for attending different incidents and an assured fast response. Thus, whenever there was an incident, the police officers after being informed would immediately swing into action. According to the respondents, this led to increased police presence in terms of patrol and fast response to repeated incidents.

The study found out that the vehicles were maintained by the lessors (motor vehicles dealers), who also allowed daily allocation of fuel. The respondents indicated that motor vehicles were serviced more promptly and released back to their duties. This meant that these vehicles were always in good condition and that the service was prompt and effective. According to the respondents, the lessor fuelled and maintained the vehicles effectively and efficiently. The respondents applauded the motor vehicle lease program as a big boost in police operations.

According to the study findings, there was a significant link between the motor vehicle lease program and the efficiency of police operations. In this case, an increase in utilisation of leased motor vehicles increased the efficiency of police operations. Other factors that highly contributed towards the efficiency of police operations under the motor vehicle lease program were; vehicle tracking and monitoring which ensured that the police officer arrived at the destination in time; fleet management of both drivers and the assets that enhanced productivity of the police service and customized financing that reduced wastage of resources, therefore, improving the efficiency of police operations as shown in Table 4.4. The findings are a confirmation of the report by PKF Consulting Limited (2017) which revealed that frequent police patrol vehicles in the area had boosted confidence amongst pupils and teachers because they could now walk freely to and from school. PKF Consulting Limited (2017) asserted that the adoption of leased motor vehicles had increased the rate of response of the police to crime incidences immensely improving business climate owing to the presence of more patrol by the police and street lights. Fuel consumption of the motor vehicle lease program moderately increased the efficiency of police operations. Meanwhile, De Jong (2017) revealed that leases are reduced by the use of spin-offs, achieved by buying back leased assets and/or replacing them by franchising or management agreements. This agrees with Spencer and Webb (2015) who found evidence that operating leases were used opportunistically.

The motor vehicle lease program increased the efficiency of police operation by enabling them to attend to their call on time, urgently visiting crime scenes and appropriately taking the necessary course of action and hence reduction of crime rate using leased vehicles which were established by Merton and Upton (2014). Table 2 shows that these vehicles were installed with appropriate equipment for vehicle tracking and monitoring just as Bharath (2013) has indicated. Bharath (2013) established that vehicle tracking and monitoring that are applied to security and safety are rapidly being adopted by several governments. Keeping track of all vehicle movements is made possible and easier by vehicle tracking and monitoring systems. According to Bharath (2013), vehicle tracking and monitoring are achieved using Geographical Positioning Software (GPS) and radio navigation system which functions through satellites and ground-based stations. The study by Bett (2012) revealed that the adoption of tracking systems is used on vehicles such as those leased by the KPS as confirmed by the results in Table 2 .

Thus, vehicle tracking and monitoring result in higher efficiency and productivity (Rahul, 2014). Nyamawe (2014) studied the adoption of ICT for tracking vehicles in Tanzania, which proposed a model for tracking over-speeding vehicles in realtime in Tanzania. The model developed was designed to constantly update the traffic police on the happenings along the Tanzanian roads and the law enforcement agents took prompt action in case of misbehaving. The study proposed that when the model was successfully implemented it would lead to positive results and contribute to road safety. The numerous studies reviewed have shown that employment of GPS and other ICT based tracking and monitoring technologies would ensure efficiency, safety, and productivity even in the police service. The adoption of such vehicle tracking and monitoring on leased 
police vehicles would yield favourable results of crime reduction. Based on the recommendations by Nyamawe (2014), there is need to develop a model for the motor vehicle lease program for the police for ensuring real-time and constant updates to the KPS. The leased motor vehicles should be fitted with monitoring technologies.

There is also the need for increasing the number of motor vehicles as well as ensuring that these vehicles were properly maintained for effectiveness in attending different incidents as well as assured fast response. Thus, whenever there was an incident, the police officers after being informed would immediately swing into action. This agrees with the study by El-Shafee, EI-Menshawi, and Saeed (2013) which revealed that vehicle tracking is adopted for particularly achieving efficiency. Accordingly, the KPS requires vehicles that are properly maintained by the motor vehicle dealers and which have an adequate daily allocation of fuel. These vehicles should always be in proper working conditions for prompt service.

\section{CONCLUSION}

There is a link between motor vehicle lease programs and efficiency of police operation where an increase in utilisation of leased motor vehicles would increase the efficiency of police operations. It is thus necessary to have enough and astute vehicles that could enhance the ability of vehicles to dispense their duties with ease. This is pertinent since this can enable their efficiency.

\section{RECOMMENDATIONS}

Various policy recommendations based on the findings were made. To begin with, the study recommends that the KPS should ensure increased use of motor vehicle lease program which has been established as effective in enhancing the efficiency of police operations in Kenya. There is need to improve response time and visible presence of the police using new police vehicles to further improve their service delivery. The KPS should actively adopt motor vehicle lease programs to enhance efficiency and effective use of resources and considerably reduce operational costs. This would provide a competitive edge by increasing productivity and reducing waste. Additionally, the KPS should provide regular training of its procurement officers about the leasing program essentials for proper motor vehicle lease program arrangement that would optimise benefits from the program. There is also the need for changing the legal and institutional framework to strengthen the laws and regulations on leasing to spur the development of leasing in the country.

\section{REFERENCES}

1. Alyosius, C., \& Lubinda, H. (2013). A Study of the Development of Leasing Industry in Zambia. International Journal of Sciences, Volume 3: Basic and Applied Research.

2. Beebe, N.L., \& Rao, V.S (2005). "Using situational crime prevention theory to explain the effectiveness of information systems security." Proceedings of the 2005 SoftWars Conference, Las Vegas, NV, Dec 2005.

3. Bett, H.K. (2012). GPS tracking technology adoption in motor vehicle insurance sector in Kenya. Doctoral dissertation, University of Nairobi, Nairobi, Kenya.

4. Bharath, C.H., Kumar, P.V., Reddy, P.A. \& Abishek, B. (2013). Vehicle tracking system using GSM and GPS (Bachelors Project Report, SAGAR Institute of Technology; Uttar Pradesh, India).

5. Clarke, R.V. (1997). Situational crime prevention: Successful case studies. Guilderland: Harrow and Heston Publishers.

6. De Jong, R. (2017). The impact of new accounting standards for leases and revenue recognition on the real estate strategy of listed hotel firms (Master Thesis, Radboud University, Nijmegen, The Netherlands).

7. El-Shafee, A., EI-Menshawi, M., \& Saeed, M. (2013).Integrating social network services with vehicle tracking technologies. .International Journal of Advanced Computer Science and Applications, 4(6).

8. Gibbs, S. (2010). Applying the theory and techniques of situational criminology to counterinsurgency operations: reducing insurgency through situational prevention (Masters Thesis, Naval Postgraduate School).

9. Kombo, D.K., \& Tromp, D.L.A. (2006). Proposal and thesis writing an. introduction. Makuyu, Kenya: Pualines Publications Africa.

10. Merton, M.H., \& Upton, C. H. (2014). Leasing, Buying and the Cost of Capital Services. The Journal of Finance.

11. Nyamawe, A.S., \& Mbosso, E. C. (2014). Road Safety: Adoption of ICT for tracking vehicles' over-speeding in Tanzania. International Journal of Computer Applications, 96(16).

12. Olana, A.A. (2016). Lease financing in Ethiopia: an assessment of five regulated lease financing companies (Masters, Thesis, Addis Ababa University, Addis Ababa, Ethiopia).

13. PKF Consulting Limited. (2017). Assessment of Implementation of the Government of Kenya Vehicle Leasing Programme. Nairobi: PKF Consulting Limited.

14. Spencer, A.W., \& Webb, T.Z. (2015). Leases: A review of contemporary academic literature relating to lessees. Accounting Horizons, 29(4), 997-1023. 